\title{
Assessment of Oral Health Care among the Institutionalized Elderly Caregivers
}

\author{
Maria Tavares ${ }^{1}$, Ana Monteiro ${ }^{1}$, Cristiana Dias $^{1}$, Inês Fonseca ${ }^{1}$, Rita Bornes ${ }^{1}$, Patrícia Couto ${ }^{1,2}$ and Nélio Veiga $^{1,2, *}$ \\ ${ }^{1}$ Health Sciences Institute, Universidade Católica Portuguesa, Viseu, Portugal \\ ${ }^{2}$ Centre for Interdisciplinary Health Research (CIIS), Universidade Católica Portuguesa, Portugal
}

*Corresponding author: Nélio Veiga, Health Sciences Institute, Universidade Católica Portuguesa, Viseu, Portugal, Tel: 00351 966454933; E-mail: nelioveiga@gmail.com

Received: 26 Feb, 2019 | Accepted: 20 Mar, 2019 | Published: 27 Mar, 2019

Citation: Tavares M, Monteiro A, Dias C, Fonseca I, Bornes R, et al. (2019) Assessment of Oral Health Care among the Institutionalized Elderly Caregivers. Int J Dent Oral Health 5(2): dx.doi.org/10.16966/2378-7090.289

Copyright: @ 2019 Tavares M, et al. This is an open-access article distributed under the terms of the Creative Commons Attribution License, which permits unrestricted use, distribution, and reproduction in any medium, provided the original author and source are credited.

\section{Abstract}

Introduction: The importance of oral hygiene among the elderly cannot be overlooked, providing physical and psychological well-being, increasing self-esteem and maintaining general health, based on the relationship between oral health and general health.

Objectives: The aim of this study consisted of the assessment of the oral health care developed by the caregivers towards their institutionalized elderly in order to understand the necessities of the elderly people and their caregivers.

Design and Methods: A cross-sectional study was developed based on a convenience sample that included a final sample of 17 caregivers of institutionalized individuals with 65 years of age or over. It was collected information based on oral hygiene habits, oral health problems, and the role of caregivers in this population and general assessment of oral health status. A questionnaire was developed and applied in the form of an interview directly to the caregivers of the nursing homes Viscondessa São Caetano and Mariana Seixas Foundation in Viseu, Portugal.

Results: When asked, caregivers reported that it is rare that the elderly complain of pain or discomfort caused by oral/dental problems. This can also be explained due to the difficulty of communication and the level of dementia that the elderly may present. Regarding dental prostheses, the caregivers considered that the elderly only sometimes or rarely it is that they sanitize them well, which demonstrates the clear need to define better primary prevention strategies for this specific population, passing mainly by oral health education and promotion among the caregivers. They also mentioned that they almost always remove the prosthesis to sleep, which a satisfactory point is considering that the nocturnal rest of the prosthesis consists of a way to avoid the appearance of pathologies such as prosthetic stomatitis.

Conclusions: Oral health training is necessary in the elderly and their caregivers, and greater support is also needed when they perform oral hygiene in order to improve their general condition oral health. It is important to highlight the positive fact that the elderly, increasingly, do the nocturnal rest of the dental prosthesis.

Keywords: Oral health; Caregivers; Elderly; Health promotion

\section{Introduction}

As a product of the evolution of medicine and the introduction of public health measures in the second half of the twentieth century, there was, as an effect, an increase in the average life expectancy. Therefore, adults aged 65 or over have health problems because of the natural aging process, and special consideration for the needs of this population is necessary [1]. Various studies demonstrate that the oral pathologies found in the elderly can be explained by the different changes that involve these patients such as the aging process itself, metabolic changes, nutritional factors, and use of medications, use of prostheses, psychopathological habits, alcohol and tobacco [2]. The importance of oral hygiene cannot be overlooked, providing physical and psychological well-being, increasing self-esteem and maintaining general health, based on the relationship between oral health and general health [1]. The myth that oral pathologies and edentulations are typical characteristics of aging has, unfortunately, been perpetuated because the prevention, treatment, and recovery of oral health care fields in which not all communities have policies well defined, especially among the elderly [3]. The implementation of a gerontological oral health prevention program should be adequate to the organizational characteristics of the institution and the beneficiaries $[4,5]$. Not only does the dentist have an active role in this prevention, but it must also be the caregiver's educator, collaborating for the organization and effectiveness of the health care routine that a dependent elder imposes $[1,2]$. In the decision to prepare preventive educational activities for geriatric oral health, the caregiver should 
be aware that the knowledge alone is not able to change habits. It is essential to use adequate means of hygiene and motivation because, although the advanced age, they maintain the capacity to learn, sometimes requiring only more motivation and guidance [1]. The aim of this study consisted of the assessment of the oral health care developed by the caregivers towards their institutionalized elderly in order to understand the necessities of the elderly people and their caregivers.

\section{Participants and Methods}

A cross-sectional study was developed between the months of March and May of 2018, based on a convenience sample that included a final sample of 17 caregivers of institutionalized elderly. The caregivers included in the study had to develop daily activities with the elderly, namely, daily hygiene, meals, and guidance. Information collected was based on oral hygiene habits, oral health problems, and the role of caregivers in this population and general assessment of oral health status. A questionnaire was developed and applied in the form of an interview directly to the caregivers of the nursing homes Viscondessa São Caetano and Mariana Seixas Foundation in Viseu, Portugal. Data analysis was carried out using the Statistical Package for Social Sciences (SPSS IBM 23.0 version). Prevalence was expressed in proportions. The information collected by the questionnaires was provided voluntarily and confidentially. The anonymity of the information collected was guaranteed by telling the caregivers not to sign their names or write down any other form of identification in any part of the questionnaire and also signed a free and informed consent form.

\section{Results}

The main results obtained for each question applied in the interview to the caregivers are presented.

\section{At the time of the oral hygiene care of the elderly, is there} always an auxiliary health professional?

In the first question, we have 9 negative answers (52.9\%), where it is stated that during the hygiene there is a professional presentation and 4 answers stating that there is a professional present.

\section{Have you ever had training in oral health care for the elderly?}

Regarding the second question, it was asked if the professionals had done some training regarding oral health care in the elderly and, if the answer was yes, what professionals the trainers were. Thus, we verified that $58.8 \%$ of the caregivers do not have specific training regarding geriatric oral hygiene. The seven caregivers that reported some kind of oral health training given by another individual mostly mentioned they had received it by dental medicine students $(57.1 \%)$, followed by dentists (42.9\%)

In your opinion, do you think older people complain about pain/discomfort caused by dental/oral problems?

In this question concerning the caregivers' knowledge about the existence of some pain/discomfort derived from dental/oral problems in the elderly, 5.9\% refer "often", 76.5\% "sometimes" and 17.6\% "rarely".

When analyzing the results of the questionnaires, we found out that the elderly don't complain much about dental discomfort or pain to their caregivers.

In your opinion, do you think the elderly care for and properly clean their dental prostheses?

Relatively to this question, we observed that the prevalent response was "sometimes" $(41.2 \%)$, considering the majority of the caregivers that most of the elderly can still independently clean their dentures properly.

\section{Do you think that the elderly remove their dentures before going to bed?}

Most caregivers report that the elderly remove the dentures almost always before going to sleep (58.8\%). However, still, $41.2 \%$ reported that their institutionalized elderly did not remove their dentures every single night before going to sleep.

\section{Discussion}

The institutionalized elderly were not always accompanied by their caregivers at the moment in which they carry out their oral hygiene. It was also verified that less than a half of the caregivers $(41.2 \%)$ received any kind of oral health knowledge in order to accompany the oral health care of their elderly. Therefore, it would be important to follow up and observe how the elderly perform their oral hygiene since they have less manual and physical capacities [6-8]. It is clearly essential that the caregivers have the necessary know-how and training so that they can help the elderly in their own oral hygiene and detect potential oral pathologies so that the individual may be directed to an oral health professional as soon as possible $[8,9]$. Institutions should invest in this type of training in order to reduce the number of oral pathologies in the elderly associated with oral hygiene $[8,9]$. When asked, caregivers reported that it is rare that the elderly complain of pain or discomfort caused by oral/dental problems. This can also be explained due to the difficulty of communication and level of mental and physical disability that the elderly may present. Regarding dental prostheses, the caregivers considered that the elderly only sometimes or rarely it is that they sanitize them well, which demonstrates the clear need to define better primary prevention strategies for this specific population, passing mainly by oral health education and promotion among the caregivers [8-10]. They also mentioned that they almost always remove the prosthesis to sleep, which a satisfactory point is considering that the nocturnal rest of the prosthesis consists of a way to avoid the appearance of pathologies such as prosthetic stomatitis.

\section{Conclusions}

Caregivers are the main source of general and oral hygiene near the institutionalized elderly and, therefore, they are considered the main professional group that should present the knowledge and responsibility in helping in the maintenance of the oral hygiene habits. Oral health training is necessary in the elderly and their caregivers, and greater support is also needed when they perform oral hygiene in order to improve their general condition and oral health. It is important to highlight the positive fact that the elderly, increasingly, do the nocturnal rest of the dental prosthesis.

\section{Acknowledgements}

The authors are deeply indebted to the directors and caregivers of the nursing homes Viscondessa São Caetano and Mariana Seixas Foundation, in Viseu, Portugal, for the participation and important contribution to this study.

\section{Author's Contributions}

Conceived and designed the study: PC, NV. Performed the data collection: AM, CD, IF, MT, RB. Analyzed the data: PC, NV. Wrote the paper: AM, CD, IF, MT, RB, PC, NV. 


\section{Competing Interests}

The authors have declared that no competing interests exist.

\section{References}

1. Paula B, Almeida M, Alves J (2014) Oral Problems in Elderly People in a Nursing Home-Literatura Review. Rev Odontol Univ Cid Sao Paulo 26: $219-226$.

2. Cornejo M, Perez G, de Lima K, Casals-Peidro E, Borrell C (2013) Oral Health-Related Quality of Life in institutionalized elderly in Barcelona (Spain). Med Oral Patol Oral Cir Bucal 18: e285-e292.

3. Llewellyn CD, Warnakulasuriya S (2003) The impact of stomatological disease on oral health-related quality of life. Eur J Oral Sci 111: 297 304.

4. Martins A, Barreto S, Pordeus I (2009) Objective and subjective factors related to self-rated oral health among the elderly. Cad Saude Publica 25: 421-435.
5. Spanish Geriatric Oral Health Research Group (2001) Oral health issues of Spanish adults aged 65 and over. The Spanish Geriatric Oral Health Research Group. Int Dent J 51: 228-234.

6. Dye BA, Selwitz RH (2005) The relationship between selected measures of periodontal status and demographic and behavioural risk factors. J Clin Periodontol 32: 798-808.

7. Harford J (2009) Population ageing and dental care. Community Dent Oral Epidemiol 37: 97-103.

8. Krustrup U, Petersen PE (2006) Periodontal conditions in 35-44 and 65-74-year-old adults in Denmark. Acta Odontol Scand 64: 65-73.

9. McGrath C, Bedi R (2001) Can dental attendance improve quality of life? Br Dent J 190: 262-265.

10. Stahlnacke K, Unell L, Soderfeldt B, Ekback G, Ordell S (2010) Selfperceived oral health among 65 and 75 years old in two Swedish counties. Swed Dent J 34: 107-119. 